\title{
Resposta de linfonodos em bovinos inoculados a campo com a vacina recombinante rSBm7462 anti Rhipicephalus (Boophilus) microplus) ${ }^{1}$
}

\author{
Lorena C. Martínez-Rodríguez², Marlene I. Vargas², Joaquín H. Patarroyo ${ }^{2 *}$, \\ Gabriel A. Tafur ${ }^{2}$ e Danilo Murta ${ }^{2}$
}

\begin{abstract}
Martínez-Rodríguez L.C., Vargas M.I., Patarroyo J.H., Tafur G.A. \& Murta D. 2014. [Lymph nodes response of cattle inoculated at field with a recombinant vaccine rSBm7462 against Rhipicephalus (Boophilus) microplus.] Resposta de linfonodos em bovinos inoculados a campo com a vacina recombinante rSBm7462 anti Rhipicephalus (Boophilus) microplus. Pesquisa Veterinária Brasileira 34(6):503-508. Laboratório de Biologia e Controle de Hematozoários e Vetores, Departamento de Veterinária, Universidade Federal de Viçosa, Campus Universitário, Viçosa, MG 36570-000, Brazil. E-mail: jpatarro@ufv.br

Exclusive chemicals dependence for the control of Rhipicephalus (Boophilus) microplus has become one of the largest scientific and economical concerns in recent years, and as a result, research to vaccine development are being undertaken. The objective of this study was evaluating the lymph nodes response of cattle immunized at field with the $r \mathrm{SBm} 7462$ anti-R. (B.) microplus peptide. Fourteen crossbred cattle (Bos taurus x Bos indicus), aged 4-10 months, were used. The animals were maintained on two farms in the north of Minas Gerais state and received three immunizations with the peptide $r \mathrm{SBm} 7462$ applied subcutaneously at 30-day intervals. Pre-scapular lymph nodes were collected surgically 15 days after each immunization and fixed in formalin for 18 hours, then, they were embedded in Paraplast subsequently and the samples were stained with Hematoxylin-Eosin (HE) technique for cellular events observation. On the other hand, in order to antigens identifying in immunized animals lymph nodes, the immunohistochemistry (IHC) with peroxidase-anti peroxidase (PAP) method was performed. Lymph node response of cattle inoculated was evaluated by analysis of germinal centers (GC) formation, medullary cords hyperplasia (MC) and antigen $r S B m 7462$ presence in PAP+ cells. This study shows that the recombinant peptide $r \mathrm{SBm} 7462$ induces a T-dependent adaptive immune response characterized on secondary lymphoid tissues by structure formation for affinity and immunological memory.
\end{abstract}

INDEX TERMS: Rhipicephalus (Boophilus) microplus, recombinant vaccine $r S B m 7462$, immunological control, lymph nodes response, cattle.

RESUMO.- A dependência exclusiva de compostos químicos para o controle de Rhipicephalus (Boophilus) microplus tornou-se uma das maiores preocupações científicas e econômicas dos últimos anos, e como consequência, estão sendo realizadas pesquisas para o desenvolvimento de vacinas. $\mathrm{O}$ objetivo deste trabalho foi avaliar a resposta de

\footnotetext{
${ }^{1}$ Recebido em 24 de janeiro de 2014.

Aceito para publicação em 28 de março de 2014.

${ }^{2}$ Laboratório de Biologia e Controle de Hematozoários e Vetores, Bioagro/Departamento de Veterinária, Universidade Federal de Viçosa, Campus Universitário, Viçosa, MG 36570-000, Brasil. *Autor para correspondência: jpatarro@ufv.br
}

linfonodos de bovinos imunizados a campo com o peptídeo $r \mathrm{SBm} 7462$ anti $R$. (B.) microplus. Foram utilizados 14 bovinos mestiços (Bos taurus x Bos indicus), com idades entre 4-10 meses, mantidos em duas propriedades rurais do norte do estado de Minas Gerais. Os animais receberam três imunizações do peptídeo $r S B m 7462$, aplicados por via subcutânea, com intervalo de 30 dias. Após 15 dias de cada imunização, os linfonodos pré-escapulares foram coletados e fixados por 18 horas em formol. Posteriormente, foram incluídos em Paraplast e as amostras foram coradas pela técnica hematoxilina-eosina (HE) para a observação de eventos celulares. Para a identificação do antígeno nos linfonodos dos animais imunizados, foi realizada a técnica 
de imuno-histoquímica (IHQ) com o método peroxidase-anti-peroxidase (PAP). A resposta de linfonodos dos bovinos inoculados foi avaliada pelas análises de formação de centros germinais (CG), hiperplasia de cordões medulares (CM) e a presença do antígeno $r \mathrm{SBm} 7462$ em células PAP+, demonstrando que o peptídeo recombinante $r \mathrm{SBm} 7462$ induz uma resposta imune adaptativa T-dependente, caracterizada nos tecidos linfóides secundários pela formação de estruturas que conferem afinidade e memória imunológica.

TERMOS DE INDEXAÇÃO: Rhipicephalus (Boophilus) microplus, vacina recombinante rSBm7462, controle imunológico, resposta linfonodos, bovinos.

\section{INTRODUÇÃO}

A dependência exclusiva de compostos químicos para o controle de Rhipicephalus (Boophilus) microplus tornou-se uma das maiores preocupações científicas e econômicas dos últimos anos, e como consequência, estão sendo realizadas pesquisas para o desenvolvimento de vacinas. Na busca de formas alternativas para o controle do parasito, foi desenvolvido um imunógeno sintético anti-R. (B.) microplus $\left(\mathrm{SBm} 7462^{\circledR}\right)$, que contém peptídeos baseados na proteína do intestino do carrapato, a Bm86 (Patarroyo et al. 2002). Quando usado em conjunto com saponina experimentalmente em bovinos de várias raças, este imunógeno alcançou uma eficácia de $81,05 \%$, tendo como parâmetros, a redução no número e no peso de fêmeas adultas, redução do peso médio dos ovos e diminuição da fertilidade (Patarroyo et al. 2002).

A demanda por vacinas parasitárias em saúde animal é crescente, e empresas remetem lucros acima de três bilhões de dólares somente nesse setor (Dalton \& Mulcahy 2001). Para diminuir as dificuldades da síntese química de peptídeos, principalmente devido ao alto custo e logística, a produção do peptídeo recombinante $\mathrm{SBm} 7462^{\circledR}$, por fermentação em leveduras Pichia pastoris, se apresenta como uma estratégia promissora para garantir grandes volumes do imunógeno e por baixo custo (Sossai et al. 2009, Neves et al. 2011, Tafur et al. 2013).

No presente estudo foram analisados eventos de respostas induzidas em linfonodos de bovinos depois de sucessivas imunizações a campo com o peptídeo recombinante $r \mathrm{SBm} 7462$.

\section{MATERIAL E MÉTODOS}

Os diferentes procedimentos experimentais que envolveram a manipulação de animais foram realizados por Médico Veterinário seguindo rigorosamente as Normas de Conduta para o Uso de Animais no Ensino, Pesquisa e Extensão da Universidade Federal de Viçosa (CEUA/UFV) número de registro 44/2013. Quatorze bovinos mestiços (Holandês x Zebu), com idades de 4-10 meses, foram utilizados. Os animais permaneceram em duas propriedades rurais do norte do estado de Minas Gerais, com criação em pasto e expostos às condições naturais. Receberam três doses de 1,5mg do peptídeo rSBm7462 (depósito de patente BR1020130266256), mais 1,5mg de saponina como adjuvante dissolvidos em 2,0mL de água ultrapura, que foram aplicados subcutaneamente no pescoço, com intervalo de 30 dias (dias 0, 30 e 60). Os linfonodos pré escapulares de 14 animais, dois em cada tempo de coleta, foram coletados no dia 0 e nos dias 15,45 e 75 dias após a primeira inoculação. As amostras coletadas no dia 0 foram consideradas controle.

Os linfonodos foram seccionados em fragmentos de $1 \mathrm{~cm}^{2}$, fixados durante 24 horas em formol tamponado $(\mathrm{pH} \mathrm{7,2)} \mathrm{e} \mathrm{con-}$ servados em álcool 70\%. Posteriormente, os fragmentos foram desidratados em soluções alcóolicas crescentes (70\%, 80\%, 90\% e $100 \%$ ), diafanizados em xilol, e incluídos em Paraplast Plus ${ }^{\circledR}$ (Sigma). Os cortes histológicos foram realizados com $5 \mu \mathrm{m}$ de espessura em micrótomo RM2255 LEICA e corados pela técnica de Hematoxilina-Eosina (HE). Os cortes foram analisados em microscópio de luz ECLIPSE E600.

Para detecção do antígeno $r \mathrm{SBm} 7462$ in situ foi utilizada a técnica de Imuno-histoquímica (IHQ) com o método Peroxidase - anti-Peroxidase (PAP) de rotina no laboratório. Brevemente, utilizou-se como anticorpo primário, o soro de coelho anti-SBm7462 diluído 1:20, incubado por 12 horas em câmera úmida; como anticorpo secundário a IgG de cabra anti coelho, diluído 1:10 e incubado a $37^{\circ} \mathrm{C}$ durante 45 minutos. Foi empregado o complexo PAP (Sigma) diluído segundo as instruções do fabricante.

\section{RESULTADOS}

\section{Avaliação histológica dos linfonodos}

A resposta dos linfonodos foi avaliada pela analise de formação de centros germinativos (CG) hiperplasia de cordões medulares (CM) e a presença de antígenos.

Na histologia dos linfonodos controles foram observados alguns folículos secundários com presença de poucas células linfocíticas (Fig.1A,C). São notáveis a zona clara (zc) e zona escura (ze) dos CG dos folículos secundários. Embora não tenha sido detectada hiperplasia de áreas paracorticais e nem de CMs (Fig.1B,D). É possível observar CG de forma inespecífica.

Quinze dias após a primeira inoculação, os linfonodos pré-escapulares revelaram hiperplasia das regiões paracorticais e formação de CGs (Fig.2A). Os CG apresentaram notável diferenciação da zc e ze, delimitadas por uma população linfocítica muito homogênea cujas células eram pequenas, com núcleo hipercromático, constituindo a zona do manto (Fig.2A), onde podiam ser observados linfoblastos, principalmente próximos à periferia desta área. Os CGs se caracterizavam por apresentar uma área mais clara constituída por células grandes, com citoplasma escasso, núcleo volumoso, cromatina frouxa ou ligeiramente condensada e com nucléolos evidentes. Também se podiam observar macrófagos e células dendríticas like (DC-like) foliculares (Fig.1B). Na camada após esta área, evidenciava-se uma região cuja população celular era mais numerosa, homogênea, com citoplasma escasso e a cromatina mais condensada, e que corresponde à zona escura. Também se observou ligeira hiperplasia dos CMs.

As amostras dos linfonodos obtidas nos dias 45 após a primeira inoculação revelaram maior número de folículos linfóides com CGs, sendo claramente identificadas as zc e ze (Fig.2 C), além de hiperplasia mais marcada nas regiões paracorticais e medulares (Fig.2D). A hiperplasia de CMs se acompanha com o surgimento de numerosas células caracterizadas como plasmócitos e linfócitos. Ao analisar os linfonodos dos animais 75 dias após a primeira imunização observaram-se os mesmos eventos de forte resposta de CGs e marcada hiperplasia nos CMs (Fig.2E,F). 

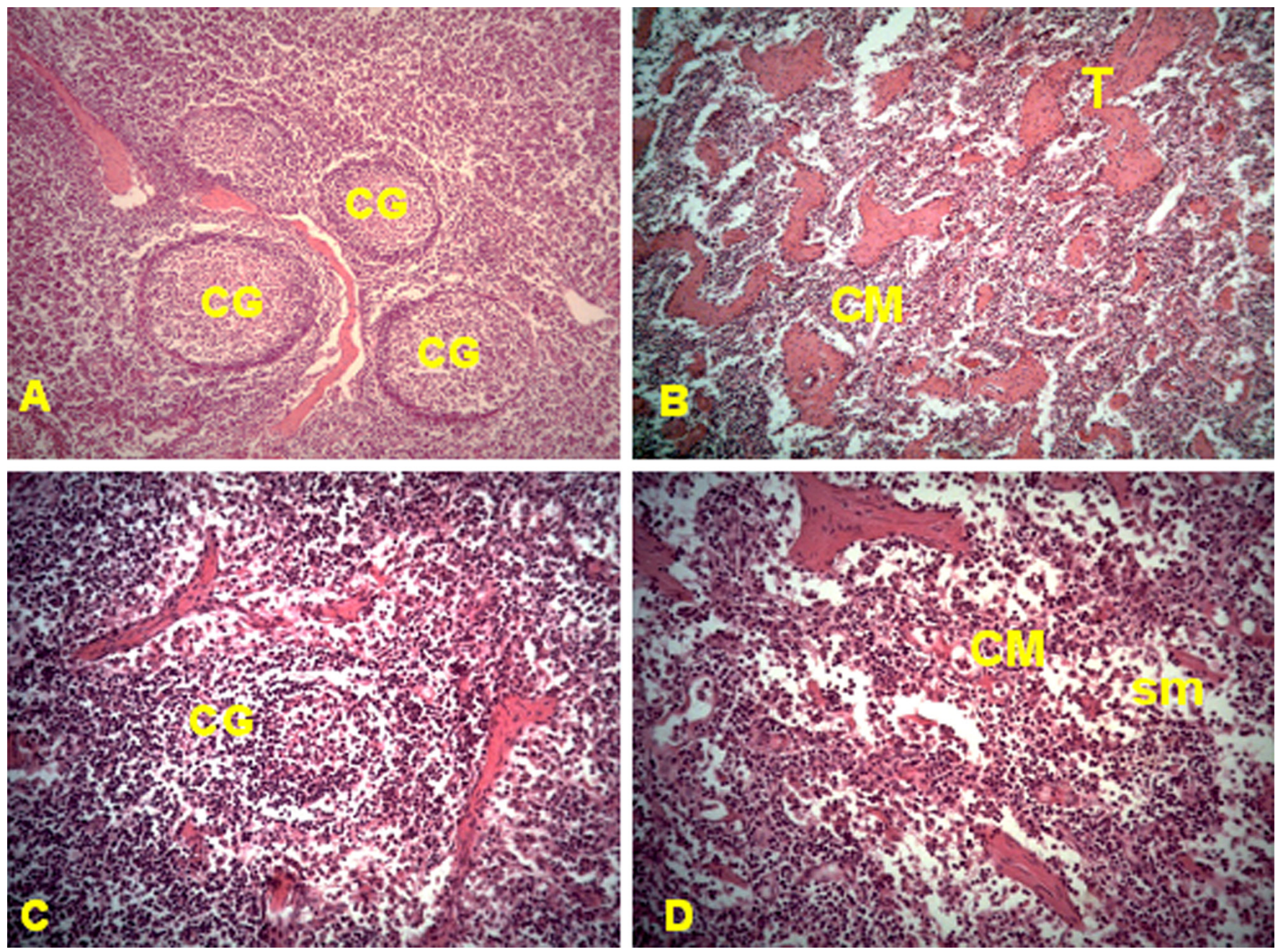

Fig.1. Linfonodos de bovinos controle não imunizados. (A) Folículos linfóides com Centros germinativos (CG). Obj.10x. (B) Cordões medulares (CM), e trabécula (T). Obj.10x. (C) Formação de CG. Obj.20x. (D) CM desorganizados e seios medulares. HE, obj.20x.

\section{Imuno-histoquímica para detecção de antígeno rSBm7462}

Nos animais controle não foram observadas células PAP+. Já nos animais imunizados com o peptídeo rSBm7462 15 dias após a primeira inoculação foram encontradas células PAP+ nos CMs e nos CGs. Aos 45 e 75 dias após a primeira imunização foi observada presença de células PAP+ na região paracortical, entretanto, foram mais intensamente marcadas nos CMs (Fig.3).

\section{DISCUSSÃO}

A formação de CGs em linfonodos dos bovinos controles corresponde a uma resposta imune não específica à vacinação, devido que a reatividade dos CGs não é regular, e não se acompanha de outros eventos celulares que indicam uma resposta imune adaptativa induzida por antígenos T-dependentes, tais como hiperplasia de áreas paracorticais e de cordões medulares (Breart \& Bousso 2006).

0 encontrado nos controles concorda com as observações de Morrison et al. (1986), que constataram que nos linfonodos periféricos de bovinos saudáveis, entre 6-12 meses de idade, em torno de 30-70\% dos folículos linfóides podem conter CGs, e que, segundo os mesmos autores, indi- caria que os linfonodos de animais normalmente saudáveis são extremamente ativos, e nesses poderia estar-se refletindo uma relativa proteção a antígenos exógenos.

Por outro lado, segundo (Romero-Palomo et al. 2013), em linfonodos de bovinos clinicamente saudáveis se identificam populações de células dendríticas, macrófagos, algumas populações de células B, e células endoteliais nas áreas dos folículos linfóides (principalmente na zona clara) e na região medular, corroborando assim os achados anteriormente descritos. Tendo em conta que os animais usados neste trabalho estavam expostos a que antígenos exógenos entrem no organismo, os achados são compatíveis ao desenvolvimento de uma resposta imune normal.

A hiperplasia das regiões paracorticais e formação de CGs com notável diferenciação da zc e ze, observados aos 15 dias após a primeira imunização concordam com as descrições de Baumjohann et al. (2013) quando afirmam que a resposta imune celular distingue-se pela hiperplasia das áreas paracorticais e surgimento de CGs, sendo característica de um imunógeno T-dependente, ou seja, uma resposta imune adaptativa que exige a interação entre células $\mathrm{T}$ e B. Respostas T-dependentes começam quando as células T e B afins para um grupo antigênico interagem nas regiões 
paracorticais, em ligações cognatas, o que pode explicar a hiperplasia das regiões paracorticais (Okada 2005).

Eventos celulares nos linfonodos dos animais quinze dias após a primeira imunização assemelham-se aos re- latos de Patarroyo et al. (2009) ao utilizarem o peptídeo sintético SBm7462 ${ }^{\circledR}$, sete dias após a primeira imunização. Segundo Bousso (2009), esta evolução de eventos nos linfonodos ocorre devido à interação entre as células
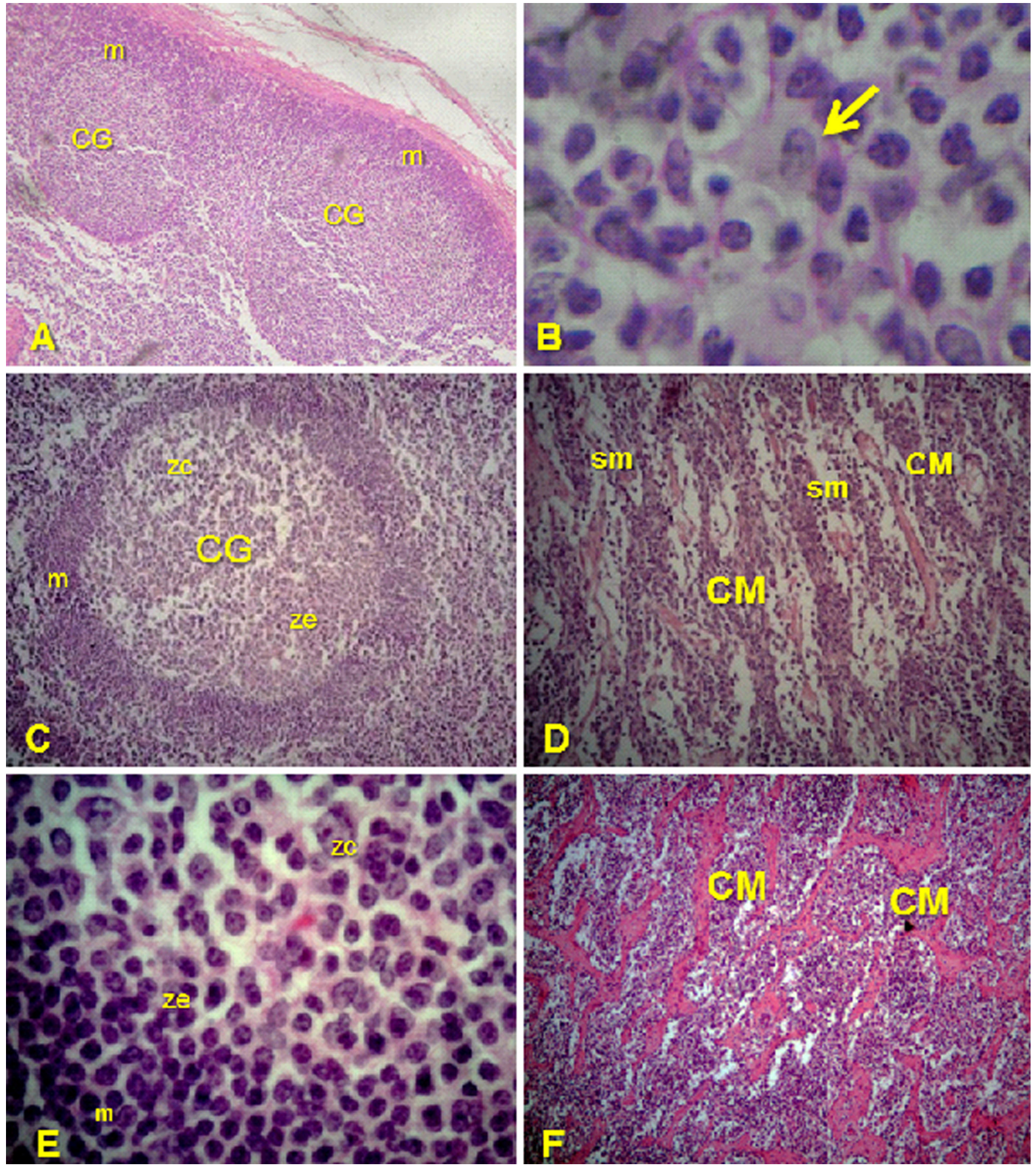

Fig. 2. Linfonodos de bovinos imunizados com o peptídeo rSBm7462. (A) Folículos linfóides com Centros germinativos (CG) 15 dias após a primeira inoculação. Obj.40x. (B) Célula dendrítica-like dentro do CG 15 dias após primeira inoculação. Obj.100x. (C) CG com zona clara (zc), zona escura (ze) e manto (m) 45 dias após a primeira inoculação. Obj.20x. (D) Cordões medulares (CM) hiperplásicos rodeados dos seios medulares (sm) aos 45 dias após a primeira inoculação. Obj.20x. (E) Detalhe do CG, mostrando zc, ze e m.75 dias após a primeira inoculação. Obj.100x. (F) CM hiperplásicos 75 dias após a primeira inoculação. H.E, obj.20x. 

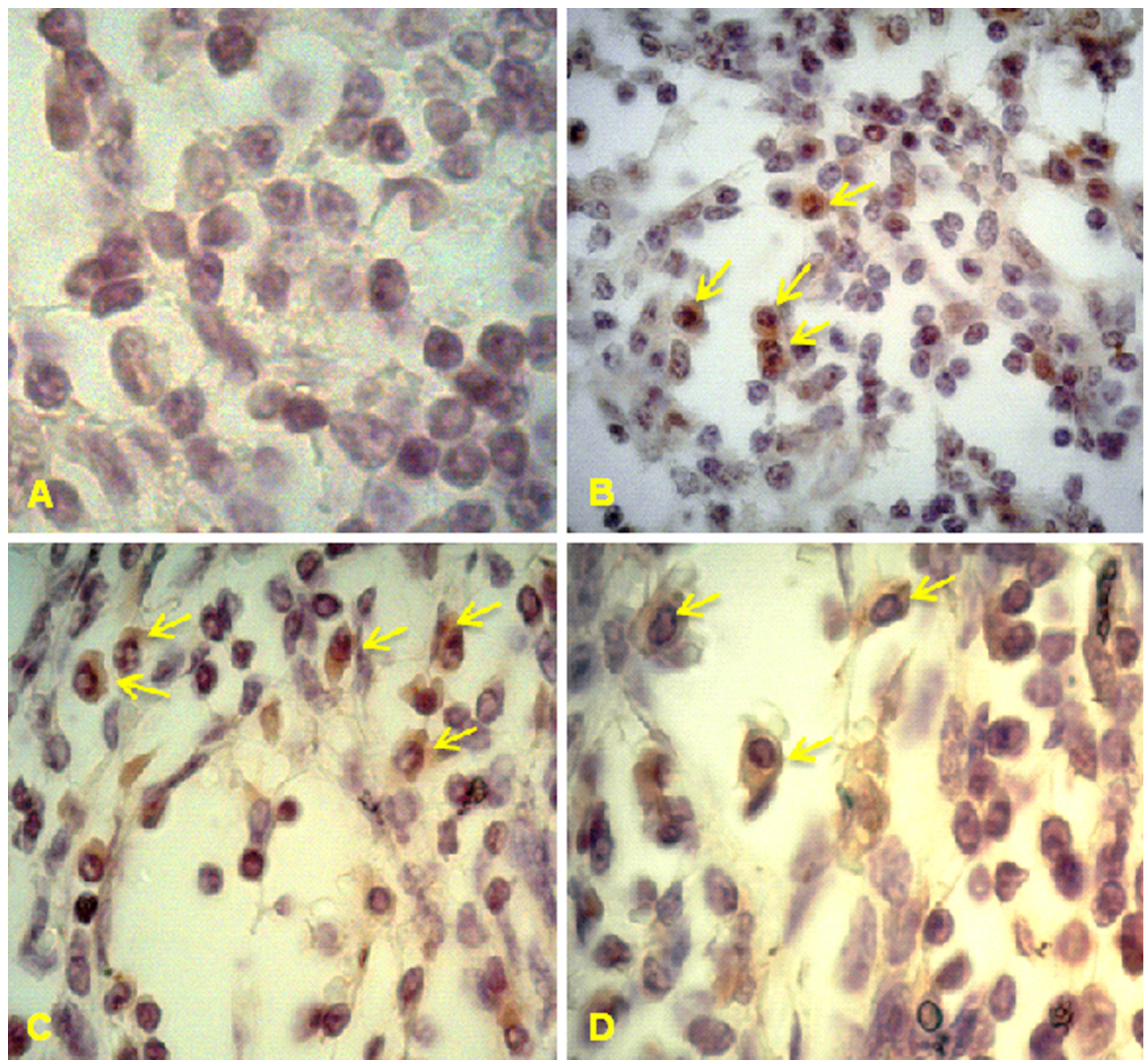

Fig.3. Linfonodos de bovinos imunizados com rSBm7462. (A) Controle, obj.100x. (B) Células PAP+ nos cordões medulares 15 dias após imunização. Obj.100x. (C) Células PAP+ em Cordões medulares (CM) 45 dias após imunização. Obj.100x. (D) Células PAP+ em Centro germinativo (CG) 75 dias após primeira imunização. Técnica Imuno-histoquímica Peroxidase - Anti-Peroxidase (PAP), obj.100x.

T naive e células apresentadoras de antígenos (APCs) mediadas pelo receptor de célula T (TCR) e o MHC para o priming das células $\mathrm{T}$.

A hiperplasia observada em áreas T-dependentes, assim como o maior número de folículos linfóides secundários observados após a segunda e terceira imunização, podem ser explicadas devido a que a resposta de células T após o segundo e terceiro desafio, geralmente é mais rápida e efetiva do que o desafio antigênico inicial, como consequência do aumento no número de células antígeno-específicas que respondem de forma mais eficiente que as células naive durante as respostas primárias (Resende 2003, Sakamoto \& Cabrera 2003).

As observações deste estudo com o imunógeno $r$ SBm7462 são semelhantes aos relatos de Tafur et al.
(2013) ao demonstrarem que as alterações histológicas nos linfonodos após a imunização com o peptídeo recombinante desencadeia uma sinapse imunológica que pode ser similar ao que foi observado com o peptídeo sintético SBm7462® descrito por Patarroyo et al. (2009), onde se demonstra que a resposta elicitada é T-dependente.

Mueller et al. (2013) afirmam que a hiperplasia de cordões medulares com o surgimento de plasmócitos, são produto da migração de linfócitos T maduros à região dos CMs em resposta a imunógenos, neste caso ao peptídeo $r \mathrm{SBm} 7462$.

Na imuno-histoquímica para a detecção de antígeno $r \mathrm{SBm} 7462$, as células PAP marcadas positivamente nas amostras aos 15, 45 e 75 dias após a primeira imunização (Fig.3), indicam que o antígeno $r S B m 7462$ é reconhecido 
por células dendríticas-like e interage com células linfocíticas concordando com os relatos de Tafur et al. (2013) e aqueles observados por Patarroyo et al. (2009) quando utilizaram o peptídeo sintético SBm7462.

Neste trabalho, as coletas de linfonodos se iniciaram 15 dias após a primeira inoculação, e foram observadas células PAP positivas, mostrando que o peptídeo é facilmente processado por células DC-like possivelmente devido à massa do peptídeo recombinante, 6,5 kDa. Se concordamos com o exposto por Patarroyo et al (2009), nos linfonodos dos animais vacinados o peptídeo recombinante poderia chegar via conduit devido a seu tamanho, posto que estes autores observaram células PAP positivas após 7 dias da imunização com o peptídeo sintético SBm7462. Assim, se as coletas dos linfonodos tivessem ocorrido antes dos quinze dias após imunização, provavelmente, esses mesmos eventos poderiam ter sido observados. Portanto, sugere-se que o peptídeo recombinante $r \mathrm{SBm} 7462$ foi capturado eficientemente pelas células DC-like, as quais corresponderiam às células PAP positivas deste trabalho.

\section{CONCLUSÕES}

0 peptídeo recombinante rSBm7462 induziu uma resposta imune adaptativa T-dependente.

O peptídeo recombinante $\mathrm{rSBm} 7462$ foi detectado nos linfonodos dos bovinos analisados através da imuno-histoquímica durante o decorrer do experimento.

Agradecimentos. - Á Patsos Biotecnologia pelo fornecimento do imunógeno e à Companhia Rural pelas facilidades nas fazendas usadas no experimento.

\section{REFERÊNCIAS}

Baumjohann D., Preite S., Reboldi A., Ronchi F., Ansel M.K., Lanzavecchia A. \& Sallusto F. 2013. Persistent antigen and germinal center B cells sustain $\mathrm{T}$ follicular helper cell responses and phenotype. Immunity 38:596-605.

Bousso P. 2009. T-cell activation by dendritic cells in the lymph node: lessons from the movies. Nature Rev. Immunol. 8:675-684.
Breart B. \& Bousso P. 2006. Cellular orchestration of T cell priming in lymph nodes. Current Opin. Immunol. 18:483-490.

Dalton J.P. \& Mulcahy G. 2001. Parasite vaccines a reality? Vet. Parasitol. 98:149-167.

Morrison W.I., Lalor P.A., Christensen A.K. \& Webster P. 2009. Cellular constituents and structural organization of bovine thymus and lymph node, p.220-251. In: Morrinson W.I. (Ed.), The Ruminant Immune System in Health and Disease. Cambridge University Press, New York . 600p.

Neves de Sousa E. 2011. Avaliação da eficácia das vacinas recombinantes $r$ Bm7462 - seq1 e $r$ Bm7462-seq4 contra o carrapato Rhipicephalus microplus. Dissertação de Mestrado em Medicina Veterinária, Universidade Federal de Viçosa, Viçosa, MG. 87p.

Okada T., Miller M.J., Parker I., Krummel M.F., Neighbors M., Hartley S.B., O'Garra A., Cahalan M.D. \& Cyster J.G. 2005. Antigen-engaged B cells undergo chemotaxis toward the $\mathrm{T}$ zone and form motile conjugates with helper T cells. PLOS Biol. 3:1047-1061.

Patarroyo J.H., Portela R.W., De Castro R.O., Pimentel J.C., Guzman F., Patarroyo M.E., Vargas M.I., Prates A.A.\& Dias Mendes M.A. 2002. Immunization of cattle with synthetic peptides derived from the Boophilus microplus gut protein (Bm86). Vet. Immunol. Immunopathol. 88:163-172.

Patarroyo J.H., Vargas M.I., Gónzalez C.Z., Guzman F., Martins-Filho O.A., Afonso L.C.C., Valente F.L., Peconick A.P., Marciano A.P., Patarroyo A.M. \& Sossai S. 2009. Immune response of bovines stimulated by synthetic vaccine SBm7462 ${ }^{\circledR}$ against Rhipicephalus (Boophilus) microplus. Vet. Parasitol. 166:333-339.

Resende M.D. 2003. Resposta celular em linfonodos de bovinos inoculados com Anaplasma marginale. Dissertação de Mestrado em Medicina Veterinária, Universidade Federal de Viçosa, Viçosa, MG. 60p.

Romero-Palomo F., Risalde M.A., Molina V., Sánchez-Cordón P.J., Pedrera M. \& Gómez-Villamandos J.C. 2013. Immunohistochemical detection of dendritic cell markers in cattle. Vet. Pathol. 50:1099-108.

Sakamoto T. \& Cabrera P.A. 2003. Immunohistochemical observations on cellular response in unilocular hydatid lesions and lymph nodes of cattle. Acta Trop. 85:271-279.

Sossai S. 2009. Expressão de quatro peptídeos recombinantes derivados do peptídeo sintético sbm7462 em Pichia pastoris e avaliação da resposta imunológica induzida em camundongos. Tese de Doutorado em Medicina Veterinária, Universidade Federal de Viçosa, Viçosa, MG. $137 p$.

Tafur G.A., Vargas M.I., Patarroyo J.H., Neves E.S., Sossai S., Araujo L., Peconick A.P \& Kalks K.H. 2013. Immunological response in bovine lymph nodes stimulated with subunits vaccines. Am. J. Immunol. 9:48-57. 